\title{
Traffic Safety Perception, Attitude, and Feeder Mode Choice of Metro Commute: Evidence from Shenzhen
}

\author{
Yuanyuan Guo ${ }^{1}$, Linchuan Yang ${ }^{2, * \mathbb{D}}$, Wenke Huang ${ }^{3}$ and Yi Guo ${ }^{4}$ \\ 1 Department of Geography and Resource Management, The Chinese University of Hong Kong, \\ Hong Kong 999077, China; guoyuanyuan@link.cuhk.edu.hk \\ 2 Department of Urban and Rural Planning, School of Architecture and Design, Southwest Jiaotong University, \\ Chengdu 611756, China \\ 3 The Research Center for Artificial Intelligence, Peng Cheng Laboratory, Shenzhen 518000, China; \\ hwk727@163.com \\ 4 Department of Geography, Hong Kong Baptist University, Hong Kong 999077, China; \\ 18481744@life.hkbu.edu.hk \\ * Correspondence: yanglc0125@swjtu.edu.cn; Tel.: +86-028-6636-6683
}

Received: 15 November 2020; Accepted: 11 December 2020; Published: 15 December 2020

\begin{abstract}
Like many other transit modes, the metro provides stop-to-stop services rather than door-to-door services, so its use undeniably involves first- and last-mile issues. Understanding the determinants of the first- and last-mile mode choice is essential. Existing literature, however, mostly overlooks the mode choice effects of traffic safety perception and attitudes toward the mode. To this end, based on a face-to-face questionnaire survey in Shenzhen, China, this study uses the two-sample t-test to confirm the systematic differences in traffic safety perception and attitudes between different subgroups and develops a series of multinomial logistic (MNL) models to identify the determinants of first- and last-mile mode choice for metro commuters. The results of this study show that: (1) Walking is the most frequently used travel mode, followed by dockless bike-sharing (DBS) and buses; (2) Variances in traffic safety perception and attitude exist across gender and location; (3) Vehicle-related crash risks discourage metro commuters from walking to/from the metro station but encourage them to use DBS and buses as feeder modes; (4) DBS-metro integration is encouraged by the attitude that DBS is quicker than buses and walking, and positive attitudes toward the bus and DBS availability are decisive for the bus-metro and DBS-metro integration, respectively; and (5) Substantial differences exist in the mode choice effects of traffic safety perception and attitudes for access and egress trips. This study provides a valuable reference for metro commuters' first- and last-mile travel mode choice, contributing to developing a sustainable urban transport system.
\end{abstract}

Keywords: traffic safety; attitude; perception; objective factor; subjective factor; dockless bike-sharing; vehicle-related crash; last mile; multinomial logistic; Shenzhen; China

\section{Introduction}

Cities are now encountering a large number of transport-related problems (mainly attributed to the extensive use of private cars or car dependency), including traffic congestion, deteriorated traffic safety situation, air pollution, increased vehicle emissions, environmental degradation, and excessive consumption of natural sources. "Reclaiming the city from cars" has constantly been advocated. Some of these vexing problems (e.g., air pollution) even adversely affect the population's health [1-3]. Additionally, as a sustainable travel mode, transit (e.g., high-speed rail, metro, commuter rail, light rail, tram, bus rapid transit, and conventional bus transit) provides a high-capacity, medium-/long-distance, and low-emission transport service for residents. It contributes to overcoming car dependence and 
redressing a wide variety of contemporary cumbersome urban problems [4]. Hence, transit has received immense popularity and gained substantial interest in recent years and has also been promoted in a host of cities worldwide to facilitate people's sustainable travel [5-7]. However, in general, it offers stop-to-stop services (rather than door-to-door services) and thus cannot cover every location of a city [8]. Poor transit accessibility, particularly in periphery areas, makes it hard, if not impossible, to reach a goal of offering convenient transport services, thereby generating first- and last-mile challenges for commuters $[9,10]$.

The metro is a popular transit mode implemented in a multitude of cities, particularly large cities. Many motorized (e.g., private car, bus, and taxi) and non-motorized (e.g., walk, bicycle, and scooter) modes have been encouraged to serve as the feeder modes of the metro (or first-/last-mile modes before/after riding the metro), thereby attracting more commuters to use the metro. In a great many car-oriented U.S. metropolitan areas, park-and-ride is preferable, due in part to high car ownership and poor transit service [11]. In European cities where cycling is pervasive and even viewed as a cultural norm, bike-and-ride has gained enormous popularity [12]. By contrast, East Asian cities such as Shanghai and Hong Kong tend to encourage the bus (e.g., feeder bus and public bus) as a way of connecting the metro $[13,14]$. In addition to these traditional feeder modes, new types of shared mobility services, such as bike-sharing and ride-sourcing, have recently been introduced to promote metro use. For example, Ma et al. [15] suggest that for a 10\% increase in bike-sharing ridership, Metrorail ridership increases by $2.8 \%$ in Washington. The majority of dockless bike-sharing (DBS) bikes are distributed around metro stations in Chinese cities [16]. These newly shared mobility services contribute to solving the first- and last-mile problem [17].

However, the decision-making process of the feeder mode choice is complicated and is determined by various factors. Previous studies offer insights into why individuals use specific transfer modes to connect transit [18]. They mainly focus on "hard" factors such as socio-economic and demographic characteristics, mandatory policies or requirements (e.g., wearing a helmet), and the physical environment such as topography, weather conditions, and the built environment at the origin and destination and around metro stations [7,19-23]. For instance, if parking space is available, people with cars and young adults with bicycles will be likely to drive or ride, respectively, to transit stations, [7,19]; transfer distance is fundamental to mode choice because different transfer modes usually correspond to different distance ranges (e.g., if the walking distance to a transit station goes beyond a certain threshold, residents will not choose to walk to transit) [23]; cycling-related facilities, such as sheltered parking spaces and bicycle lanes, contribute to a bike-friendly environment, thereby attracting bike-sharing-metro integration [24]. Besides, "soft" factors on the psychological aspect, such as attitude and perception, are postulated to determine travel behaviors, which has prominently been discussed in socio-psychological theories such as the theory of planned behavior (TPB) [25]. Traditional travel behavior literature also recurrently suggests that traffic safety and individual attitudes are crucial in shaping travel mode choice (e.g., $[18,19])$. The perceived traffic safety/risk affects the choice of self-controlled travel modes, such as driving and cycling [26-28]. The role of attitudes in mode choices could be as important as or even more important than the physical environment and socio-economic characteristics [29-31], but this is still inconclusive. For example, individuals with favorable attitudes toward a specific travel mode may likely use that mode [18,32]. Even though the effects of traffic safety perception and attitudes on mode choice are widely acknowledged, to the knowledge of the authors, limited studies have investigated (1) the impacts of the two psychological factors on the feeder mode choice of the metro; and (2) how the impacts vary across metro commuters' first- and last-mile trips.

To this end, based on a case study of Shenzhen, China, this study explores how the perceived traffic safety and the attitude toward transfer modes correlate to the feeder mode choice of metro commuters. A field questionnaire survey was conducted at many metro stations in Shenzhen, in which the metro commuter's transfer mode for the access/egress trip has been examined. The two-sample $\mathrm{t}$-test is used to confirm the systematic differences in traffic safety perception and attitudes between different subgroups, and a series of multinomial logistic (MNL) models is developed to identify the 
determinants of first- and last-mile mode choice for metro commuters. The study aims to address the following four research questions: (1) What is the mode share of access/egress trips in today's Chinese mega cities? (2) Do traffic safety perceptions and attitudes vary by gender and location? (3) Are perceived traffic safety and attitudes toward transfer modes important in determining the transfer mode choice? (4) Are the effects of perceived traffic safety and attitudes toward the mode different between access and egress trips? We believe that this study contributes to the promotion of green and healthy urban mobility and serves as a valuable reference for Chinese mega cities and other settings with similar traffic conditions.

The remainder of the paper is organized as follows. Section 2 introduces existing feed modes. Section 3 reviews the literature on the effects of perceived traffic safety and attitudes on feeder mode choice. Section 4 presents the study context, questionnaire survey, and methodologies. Section 5 offers the analyses of feeder mode share, the individual variance in perceived traffic safety and attitude, and the modeling results. Section 6 provides policy implications, research limitations, and avenues for future research. The final section (Section 7) concludes the paper.

\section{Summary of Existing Feed Modes}

Walking, a travel mode with economic, environmental, social, and health impacts [10,33], is often used to reach a transit station (walk-and-ride). However, it requires the use of the human body as a travel machine. Therefore, it is significantly restricted by travel distance [21]. Generally, the willingness to walk can be well described by distance decay curves: after $800-1000 \mathrm{~m}$, the mode share of walking declines sharply.

The bicycle's integration with transit (bike-and-ride) is also common for commuters. The synergy of the bicycle and transit for access/egress trips can be summarized into three patterns: bicycle-and-transit, transit-and-bicycle, and bicycle-on-transit (taking a bicycle on transit) [34,35]. There are many preconditions for the bicycle-and-transit and transit-and-bicycle patterns, such as the ownership of bicycles, available secure parking spaces, and parking facilities (e.g., shelter and parking dock) around transit stations [36]. However, the bicycle-on-transit pattern is usually constrained by the parking space or capacity on transit, which may bring conflicts between regular transit passengers and bicycle-transit users [35]. Recently, bike-sharing services, including docked and dockless programs, have been introduced to various cities (e.g., Paris, Singapore, and Shanghai). This makes the bike-metro integration smarter, greener, and more economical because there is no need to bring bikes on transit and worry about the issues of theft and maintenance [16,37].

As for motorized feeder modes, the motorcycle (two-/three-wheeled motor vehicle), which usually carries 1-2 passengers, has a similar function with the taxi in many developing countries, such as China, Thailand, Vietnam, and India $[38,39]$. Motorcycle drivers always wait at large-scale residential areas and the exits of transit stations and solicit passengers. They often ride through narrow spaces during traffic jams. Thus, as for passengers, the motorcycle is fast (or time-saving) and easy to access. Moreover, in larger metropolitan areas, feeder buses, which are commonly operated in two forms-demand-responsive transit and fixed-route transit [40]—have been introduced by transit agencies to residents, especially those with poor transit accessibility. They perform well when the to-transit distance is long [22].

The private car is an option to access transit stations, and it involves two manners: park \& ride and kiss \& ride (i.e., passenger drop-off) [21]. The availability of park \& ride facilities is a key factor for commuters with cars [20]. However, using the private car as the feeder mode of transit, particularly for the park \& ride pattern, is more common in remote locations than downtown [41].

Other modes such as traditional and electric scooters, e-bike, taxi, and ride-hailing can serve as the feeder modes of transit. However, few empirical studies have discussed their integration with transit [42]. 


\section{Related Studies}

\subsection{Perceived Traffic Safety and Last-Mile Mode Choice}

Traffic safety is usually measured by how unlikely accidents occur. It is reported that traffic accidents kill about 1.2 million people all over the world each year [43]. Traffic safety is determined by many factors, such as road characteristics, climate and weather, and-perhaps most importantly-vehicle speeds [44]. Previous research confirmed that the higher the speed, the greater the possibility of traffic accidents [28,45].

Perceived traffic safety refers to individuals' perceived likelihood of an accident-free traffic outcome (i.e., avoiding traffic accident and crash) [43,46]. It varies from person to person based on their background (information and experience) and how they deal with risks [47,48]. For example, Salonen indicated that men have a higher level of traffic safety awareness, in-vehicle security, and emergency management than women [43]. Bordagaray et al. confirmed that young adults (aged 34 years or below) perceive traffic safety as less important than older people do [1]. Moreover, the built environment is associated with people's safety perceptions. Intersection density and the presence of major road crossings en-route were found to insensibly affect the individual's perception of safety, such as the fear of collision [28]. Safety concerns also come from heavy traffic, such as high volume/speed of vehicles on streets [49,50].

Furthermore, the perception of traffic safety may significantly affect mode choice decision [51]. According to the TPB model, perceived behavior control, which means the perceived difficulty in or ease of performing a behavior, is one of the socio-cognitive factors determining the individual's behavioral intention [25]. Moreover, a model for passenger transport developed by Van Wee [52] summarizes elements shaping travel behavior, including activity locations, transport resistances, needs, opportunities, and abilities. Typically, travel resistance consists of time, money, and other non-monetary costs, such as the perceived risk of traffic. Specifically, the perception that a certain type of transport mode is unsafe can be a psychological barrier to its use [53]. According to some empirical studies, the number of occurred crashes can directly affect the safety perception of pedestrians and bicyclists [54], thereby influencing active transport behaviors. Aziz et al. [55] also indicated that decreasing traffic crashes on pedestrians and bicyclists led to an increase in the likelihood of walking and cycling behavior. A recent study focusing on new safety challenges that autonomous vehicles (AVs) introduce indicates that, among road users, cyclists have the lowest level of perceived safety, followed by pedestrians and drivers, when their activities are near an AV [56].

\subsection{Attitude and Last-Mile Mode Choice}

Attitude can be defined as "global and relatively stable evaluations that people do about persons, things or ideas" [57]. Thus, attitudes involve positive or negative views that people have in terms of any aspect of reality [32,58]. According to existing literature [50,52,53], travel-related attitudes are usually connected to preferences for destinations, routes, activities, and modes of transport. A more general understanding of travel-related attitudes may also correlate with the individual's beliefs (e.g., environmentalism) [59].

Some behavior theories, such as the theory of reasoned action (TRA) and its extension, namely the TPB, emphasized that the individual's travel behavior is significantly influenced by attitudes. In TRA and TPB models, attitude is a predictor of the individual's behavioral intention, which is a predictor of behaviors $[25,60,61]$. Travel behavior literature has well recognized the role of attitude in shaping travel behavior $[32,62,63]$. In particular, the individual's attitude toward travel modes is evidenced to affect mode choice. For example, positive attitudes toward walking and cycling are related to frequent physical activities (through active travel), discouraging the motorized mode usage (e.g., car and bus) [32]. Thøgersen [64] found that a good attitude toward transit can predict transit use among Danish residents based on a panel survey during 1998-2000. Tran et al. [59] investigated the specific attitudes toward cars and buses and how such attitudes affect mode choice. They concluded that 
attitudes toward car use significantly affect the bus utility. Through a qualitative study in Porto (Portugal), Beirão and Sarsfield Cabral [65] also demonstrated the significant role of attitude in influencing the mode switch (from the car and public transit) for commuters. They suggested that improving the levels or images of public transit services could be effective to attract occasional public transport users and car users. Additionally, the relative attitudes among transport modes play a crucial role in affecting mode choice. He and Thøgersen [66] revealed that people's favorable attitudes toward transit (relative to cars) make transit more attractive. In a similar vein, people who prefer cars to public transport tend to travel by car.

In addition to the specific attitude toward the travel mode, the travel behavior effects of general attitudes with a broad concept have been studied. For example, a positive attitude toward physical activity promotes bicycling and walking behaviors [67]. Based on samples of Swedish commuters, Johansson et al. [27] found that attitudes toward flexibility and comfort influence mode choice. Additionally, some studies incorporated attitudes to analyze the influences of environmental awareness and sustainability concerns about mode choice and demonstrated the role of these attitudes $[32,68]$.

However, studies on the effect of traffic safety and attitude toward mode choice are still scarce in terms of the specific condition of feeder trips. Previous studies have mostly investigated mode choice for general trips but paid limited attention to the first- and last-mile trips. Therefore, more sophisticated analyses are indispensable to explore the associations between traffic safety, attitude, and feeder mode choice.

\section{Data and Methodology}

\subsection{Study Area: Shenzhen}

Shenzhen, a famous international metropolis located on the southern coast of China and adjacent to Hong Kong, is selected as our study area. In 2019, Shenzhen had a population of 13.44 million and covered an area of $1997 \mathrm{~km}^{2}$, indicating a high population density $\left(6730\right.$ people $\left./ \mathrm{km}^{2}\right)$. Shenzhen had a vast amount of GDP in 2019 (390.34 billion dollars), ranking third in China. Over the last ten years, Shenzhen has widely been known as one of the Tier 1 cities in China (the other three cities are Beijing, Shanghai, and Guangzhou) [69]. Compared to other Asian modern cities, the GDP of Shenzhen is only smaller than Tokyo but larger than Singapore, Hong Kong, and Seoul. Additionally, Shenzhen has a large-scale metro system, which has opened since 28 December 2004. As of October 2020, Shenzhen has 11 metro lines, 237 metro stations, and a total mileage of $411 \mathrm{~km}$ (Figure 1). The daily ridership in 2018 was 5.14 million [37], ranking fourth in Mainland China. It is comparable to Hong Kong and Seoul but falls behind Tokyo. Therefore, Shenzhen is a representative modern city in China and also in East Asia.

The metro is an important travel mode for commuters, accounting for over $40 \%$ of trips taken by residents [37]. According to an online report issued by the Shenzhen Rail Transit Construction Headquarters Office, the average daily metro ridership and the per-km passenger volume in 2019 were 5.57 million and 19.2 thousand, respectively (Top Five in Mainland China) [70]. After the city has officially been designated as a "Transit Metropolis (gongjiao dushi)" by the Ministry of Transport of China, the local government has implemented a series of policy measures, such as establishing bus stops and allocating shared bikes (i.e., public bicycle and DBS) around metro stations, to promote the seamless connection between the metro and its feeder modes.

Although Shenzhen witnessed an accomplished development of public transit, it experienced a sharp growth of private cars over the last decade. As of 2018, the number of motor vehicles in Shenzhen was approximately 3.37 million, and the total length of the road was $6443 \mathrm{~km}$. This means that the density of motor vehicles ( 522.58 vehicles $/ \mathrm{km}$ ) is very high, which may result in an increased risk of traffic safety issues such as pedestrian/bicycle/vehicle-related crashes. Obviously, traffic safety issues are more acute in metro catchment areas with concentrated populations and vehicles than in other areas. 


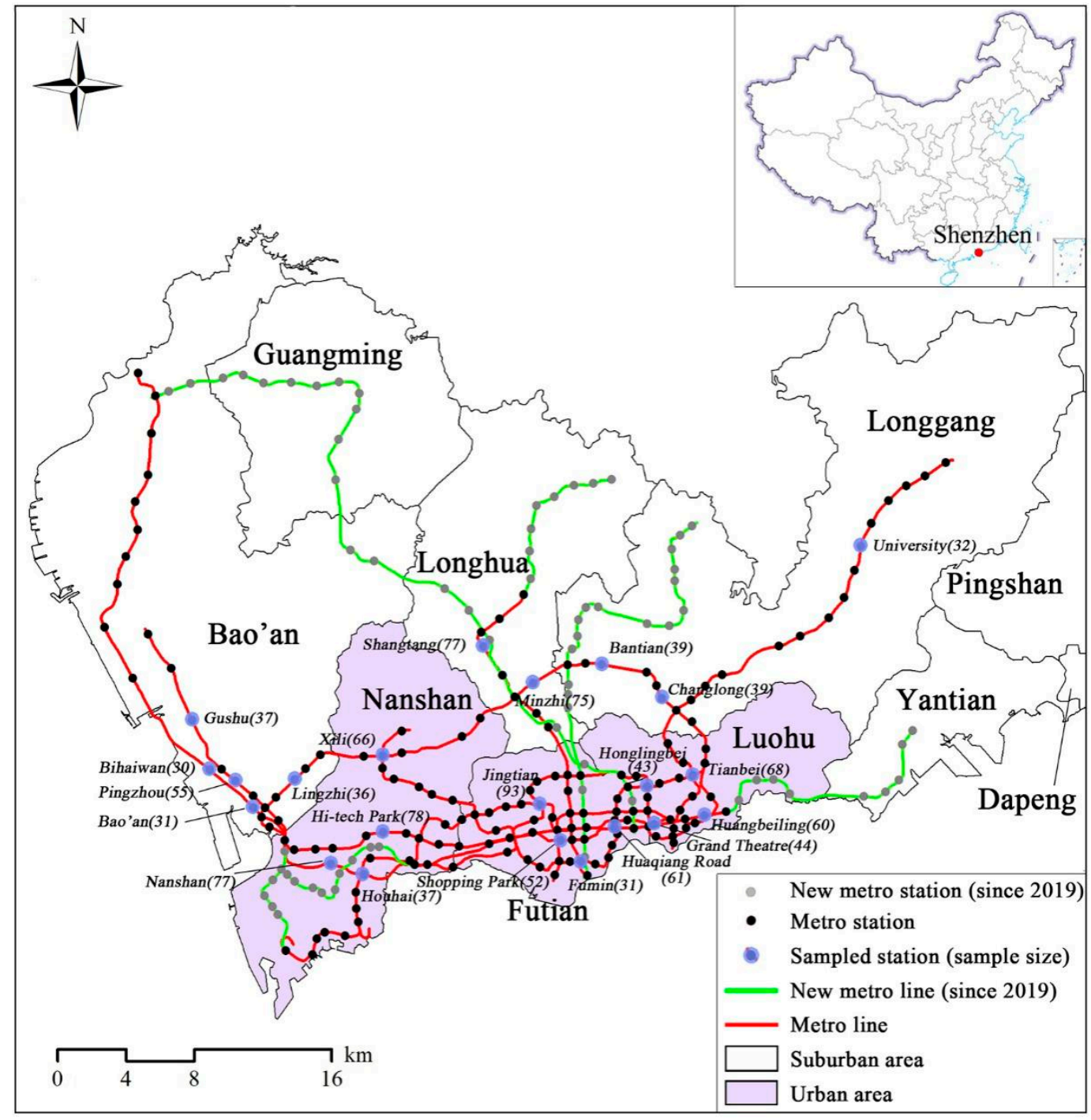

Figure 1. Study context of Shenzhen. Note: Since 2019, 70 new metro stations and $114.3 \mathrm{~km}$ metro lines have been built [37].

\subsection{Data and Variables}

\subsubsection{Data}

As formerly mentioned, this study aims to identify factors influencing the feeder mode of the metro, paying special attention to perceived traffic safety and attitude; and feeder mode includes walking, DBS, private bicycles, buses, taxi/Didi, cars, scooters, and other modes. We, therefore, collected the data by conducting a field questionnaire survey at 22 randomly selected metro stations in Shenzhen, China, between October and November in 2019 (Figure 1). During the survey, rainy days were excluded. Metro users who entered or left from the metro station during 7:30 a.m. and 9:00 a.m. were randomly selected as the survey samples. Given that metro commuters are usually in a hurry during the morning peak time, the respondents were requested to keep a leaflet with a quick response (QR) code. Thus, metro passengers can complete the questionnaire in their leisure time by scanning the QR code.

The questionnaire was composed of several parts, including transfer mode choice, the individual's perceptions of and attitudes toward specific transport modes, and socio-demographic characteristics. In this study, traffic safety concerns were measured in a subjective way by considering two safety issues: pedestrian-bicycle crash and pedestrian/bicycle-vehicle crash. Metro users' attitudes toward typical first-/last- mile travel modes were investigated. Additionally, relative attitudes of metro users, 
such as DBS versus walking and DBS versus bus, were recorded. Furthermore, questions on the attitude toward metro users' ability to access DBS and buses and the attitude toward daily physical activities were asked.

Questions related to traffic safety perception were designed by referring to the "Neighborhood Environment Walkability Scale (NEWS)" questionnaire, which includes questions on individuals' perceptions of the environment [71]. Based on the NEWS, a four-point Likert scale (i.e., "strongly disagree" $=1$, "somewhat disagree" $=2$, "somewhat agree" $=3$, and "strongly agree" $=4$ ) was adopted to assess the perceived traffic safety. Similarly, individual's attitudes were evaluated by the four-point Likert scale, thereby making the results comparable to those of perceived traffic safety.

We received 1702 questionnaires, 1167 of which were valid (valid rate $=68.57 \%$ ). The number of valid questionnaires for each metro station ranged from 30 to 93 (Figure 1). Among valid samples, 1086 respondents chose walking, DBS, or buses in access trips, while 1108 adopted one of these three modes to finish their egress trips. These three popular feeder modes account for $93.06 \%$ and $94.94 \%$ of the total trips in the access and egress scenarios, respectively, while other modes (e.g., private bicycle, taxi, Didi, and scooter) constitute less than $7 \%$.

\subsubsection{Variables}

Table 1 shows the measurements and descriptive statistics of perceived traffic safety variables, attitude variables, and socio-demographic characteristics.

The average score of bicycle crash is approximately 3 ("somewhat agree"), which is modestly larger than vehicle crash. This observation indicates that the bicycle-related crash could be a major safety concern for metro users in first-/last-mile trips and may significantly affect metro commuters' first-/last-mile mode choice. Similarly, metro commuters may face a risk of crashes with vehicles along their feeder routes. As for the transport mode, metro riders usually have a positive attitude or fondness toward non-motorized modes (including walking and cycling) but a negative attitude toward the bus (the average score is only 2.3).

As for the access trip connecting home and the metro station, DBS/bus availability involves how easy to find DBS bikes/bus stops around their home. In terms of the egress trip connecting the metro station and the workplace, DBS/bus availability means that how easy to find DBS bikes/bus stops around metro exits. However, we observe that many metro users agree that it is not easy to find a DBS bike for both access and egress trips. By contrast, metro users hold an attitude that the bus stop is relatively easy to access. Moreover, respondents usually want to have some daily physical activities.

Table 1 indicates that more male passengers (59\%) participated in the survey than female passengers (41\%); most respondents were young ( $84 \%$ aged 35 years or below), well-educated $(88 \%$ hold a bachelor degree or above), and middle-income earners (68\% earn between 5000 and 14,999 RMB monthly); the respondents usually did not own a bicycle; and minimal differences in socio-demographic characteristics existed between the two scenarios. However, most access trips occurred in suburban areas $(56.54 \%)$, while egress trips were largely concentrated in urban areas $(79.69 \%)$. This observation indicates the jobs-housing imbalance in Shenzhen: Many metro commuters live in suburban areas because of low housing rent but work in urban areas with more job opportunities.

The feeder trip distance is calculated via a geographic information system by connecting the geo-coded home/workplace addresses and the metro station reported by the respondents. The result shows that metro users have a longer transfer distance of home-metro feeder trips (access trip, $766 \mathrm{~m}$ ) than that of the workplace-metro feeder trips (egress trip, $565 \mathrm{~m}$ ). 
Table 1. Measurements and statistics of variables of safety, attitude, and socio-demographic characteristics $(N($ access trips $)=1086 ; N($ egress trips $)=1108)$.

\begin{tabular}{|c|c|c|c|c|}
\hline \multirow{2}{*}{ Variable } & \multirow{2}{*}{ Description } & \multirow{2}{*}{ Category and/or Code } & \multicolumn{2}{|c|}{ Mean/Percentage } \\
\hline & & & Access Trip & Egress Trip \\
\hline \multicolumn{5}{|c|}{ Explanatory variables: safety and attitude } \\
\hline Bicycle crash & I have safety concerns about crashes with a bicycle along the feeder trip. & \multirow{11}{*}{$\begin{array}{l}\text { Strongly disagree }=1 ; \\
\text { Somewhat disagree }=2 ; \\
\text { Somewhat agree }=3 ; \text { and } \\
\text { Strongly agree }=4\end{array}$} & 3.04 & 3.15 \\
\hline Vehicle crash & I have safety concerns about crashes with a vehicle along the feeder trip. & & 2.45 & 2.43 \\
\hline Cycling & I like to ride a bicycle. & & 3.09 & 3.09 \\
\hline Walking & I like to walk. & & 3.15 & 3.14 \\
\hline Bus & I like to take a bus. & & 2.34 & 2.33 \\
\hline DBS & I like DBS. & & 2.97 & 2.97 \\
\hline DBS vs. walking & I think DBS is quicker than walking to connect the metro. & & 2.80 & 2.81 \\
\hline DBS vs. bus & I think DBS is quicker than buses to connect the metro. & & 2.76 & 2.77 \\
\hline Easy to take a bus & I think it is easy to take a bus to connect the metro. & & 2.95 & 2.88 \\
\hline Easy to find DBS & I think it is easy to search for a DBS bike to connect the metro. & & 2.29 & 2.60 \\
\hline Physical activity & I would like to have daily physical activities. & & 3.14 & 3.14 \\
\hline \multicolumn{5}{|c|}{ Control variables: socio-demographic characteristics } \\
\hline \multirow[t]{2}{*}{ Gender } & \multirow[t]{2}{*}{ Male or female } & Female & $41.16 \%$ & $41.34 \%$ \\
\hline & & Male & $58.84 \%$ & $58.66 \%$ \\
\hline \multirow[t]{4}{*}{ Age } & \multirow[t]{4}{*}{ / } & $<25$ years & $32.23 \%$ & $32.13 \%$ \\
\hline & & 26 to 35 years & $51.66 \%$ & $52.08 \%$ \\
\hline & & 36 to 45 years & $12.80 \%$ & $12.73 \%$ \\
\hline & & $>46$ years & $3.31 \%$ & $3.07 \%$ \\
\hline \multirow{4}{*}{ Education } & \multirow{4}{*}{ Education status } & Middle school or below & $1.93 \%$ & $1.99 \%$ \\
\hline & & High school & $9.85 \%$ & $10.11 \%$ \\
\hline & & University/College & $75.32 \%$ & $75.00 \%$ \\
\hline & & Graduate institute & $12.89 \%$ & $12.91 \%$ \\
\hline \multirow[t]{4}{*}{ Income } & \multirow[t]{4}{*}{ Monthly personal income } & $<4999$ RMB & $11.97 \%$ & $11.82 \%$ \\
\hline & & 5000 to 9999 RMB & $44.94 \%$ & $44.68 \%$ \\
\hline & & 10,000 to $14,999 \mathrm{RMB}$ & $23.39 \%$ & $23.29 \%$ \\
\hline & & $>15,000 \mathrm{RMB}$ & $19.71 \%$ & $20.22 \%$ \\
\hline \multirow{2}{*}{ Bicycle ownership } & & No & $89.32 \%$ & $88.36 \%$ \\
\hline & & Yes & $10.68 \%$ & $11.64 \%$ \\
\hline \multirow{2}{*}{ Location } & \multirow{2}{*}{ Location of the feeder trip } & Urban area & $43.46 \%$ & $79.69 \%$ \\
\hline & & Suburban area & $56.54 \%$ & $20.31 \%$ \\
\hline Transfer distance & The Euclidean distance of the trip $(\mathrm{km})$ & & 0.766 & 0.565 \\
\hline
\end{tabular}




\subsection{Methodology}

This study applies two analysis approaches, namely the two-sample (two-tailed) t-test and the multinomial logistic (MNL) model.

First, the two-tailed t-test is widely used to determine the statistical significance of difference between the means of two groups. In this study, it was performed to identify the variance in traffic safety perception and attitude among groups segmented by gender and location (male vs. female groups, and passenger groups working/living in urban areas vs. those working/living in suburban areas).

Second, the MNL model is a popular method to relate a nominal (or categorical) outcome variable to its predictors [72]. One of its assumptions is that the random components of the utilities of different choices (error terms) are independent and identically distributed according to a Gumbel distribution (extreme value distribution). Moreover, the MNL model has the property of proportional substitution across alternatives (e.g., independent from irrelevant alternatives, or IIA) (recall the red bus-blue bus problem). In this study, feeder mode choices are typically nominal outcomes (with no natural ordering) and composed of three categories (i.e., walking, DBS, and bus). Thus, the MNL model fits well with our research and thus was used to identify how the factors of perceived traffic safety and attitudes are associated with first-/last-mile mode choice under two scenarios of access and egress feeder trips. More information on the MNL model can be found in [73].

Two kinds of transfer trips, namely access trips and egress trips, were considered. Thus, two MNL models (Access MNL model and Egress MNL model) are developed. As the name explicitly states, the Access MNL model scrutinizes the determinants of feeder mode choice for access trips, while the Egress MNL model does so for egress trips. Additionally, collinearity was assessed by calculating the variance inflation factor (VIF), and the result shows that the VIF values of all variables were less than 5 .

\section{Results}

\subsection{Feeder Mode Choice of the Metro}

Figure 2 presents the share of the three feeder modes. It suggests that walking is the most frequently used mode by metro commuters for first- and last-mile trips, which is in line with many previous studies $[22,23,34]$. For either access or egress trips, the mode share of walking (more than $70 \%$ ) is far larger than DBS (approximately 15\%), closely followed by buses (about 10\%). The relatively high share of DBS as the feeder mode of the metro demonstrates the popularity of DBS-metro integration in the study context. Compared with the share of the traditional docked bike-sharing (public bicycles) (4.4\% in Nanjing [22] and 7.04\% in Beijing) [23], DBS accounts for a larger market share, which reveals that it outperforms public bicycles in serving as the feeder mode of the metro. Furthermore, walking is more commonly adopted in egress trips than in access trips (difference in mode share $=5 \%$ ). Few differences are observed between the two scenarios for DBS-metro integration, while metro users have a higher willingness to transfer by buses for home-metro connection than workplace-metro connection.

Table 2 reveals the feeder mode choice of men and women. It indicates that feeder mode choices substantially differ across genders. The male group has a similar share of walking with the female group but a higher share of DBS and a lower share of buses for access trips. As for egress trips, the differences in the share of three feeder modes between the two groups are subtle.

Table 3 shows the feeder mode choice in urban and suburban areas. Walking is preferable for metro users who live/work in urban areas than those living/working in suburban areas. A possible explanation for this observation is that the metro transit system is less developed in suburban areas, thereby generating a longer transfer distance unsuitable for walking but suitable for riding buses. 


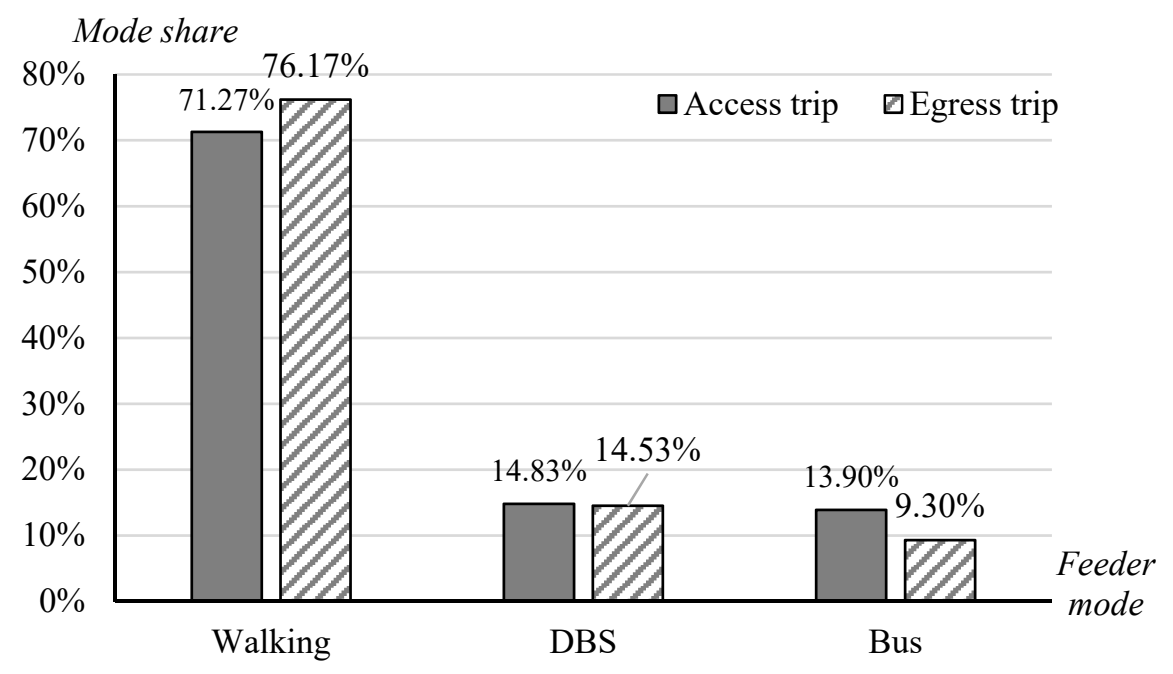

Figure 2. Share of the three feeder modes.

Table 2. Feeder mode choice of men and women.

\begin{tabular}{ccccc}
\hline \multirow{2}{*}{ Mode } & \multicolumn{2}{c}{ Access Trip } & \multicolumn{2}{c}{ Egress Trip } \\
\cline { 2 - 5 } & Female & Male & Female & Male \\
\hline Walking & $72.71 \%$ & $70.27 \%$ & $76.64 \%$ & $75.85 \%$ \\
DBS & $11.41 \%$ & $17.21 \%$ & $13.54 \%$ & $15.23 \%$ \\
Bus & $15.88 \%$ & $12.52 \%$ & $9.83 \%$ & $8.92 \%$ \\
\hline
\end{tabular}

Table 3. Feeder mode choice in urban and suburban areas.

\begin{tabular}{ccccc}
\hline \multirow{2}{*}{ Mode } & \multicolumn{2}{c}{ Access Trip } & \multicolumn{2}{c}{ Egress Trip } \\
\cline { 2 - 5 } & Urban Area & Suburban Area & Urban Area & Suburban Area \\
\hline Walking & $75.85 \%$ & $67.75 \%$ & $80.29 \%$ & $60.00 \%$ \\
DBS & $16.31 \%$ & $13.68 \%$ & $12.68 \%$ & $21.78 \%$ \\
Bus & $7.84 \%$ & $18.57 \%$ & $7.02 \%$ & $18.22 \%$ \\
\hline
\end{tabular}

\subsection{Variance in Perceived Traffic Safety and Attitude}

Ample evidence shows that traffic safety perception is associated with gender [56,74] and location [75]. We, therefore, considered the variance in perceived traffic safety across genders and home/workplace locations. However, the variance in attitudes is usually correlated with socio-demographic characteristics, such as gender [43], so we made a comparison between male and female groups. We calculated the mean difference along two dimensions (gender (female versus male) and location (urban versus suburban areas)) and conducted two-sample t-tests. The mean differences were obtained as follows: male metro users minus female metro users, and metro users with a home/workplace located in urban areas minus those with a home/workplace situated in suburban areas.

Table 4 shows the result of the two-sample t-test. The perceived traffic safety significantly varies across gender and location. Compared with male metro users, female counterparts perceive a higher risk of vehicle-related crashes but a statistically equivalent risk of bicycle-related crashes. Moreover, the perceived risk of bicycle and vehicle crashes could be more obvious in suburban areas than in urban areas for access trips (connecting the home and the metro), but the reverse is true for egress trips (connecting the workplace and the metro). 
Table 4. Two-sample t-test results of individual variance in perceived traffic safety and attitude.

\begin{tabular}{|c|c|c|c|c|c|c|}
\hline \multirow{2}{*}{ Variable } & \multicolumn{3}{|c|}{ Male vs. Female Passengers } & \multicolumn{3}{|c|}{ Urban vs. Suburban Location } \\
\hline & Difference of Mean & $F$ & Sig. & Difference of Mean & $F$ & Sig. \\
\hline \multicolumn{7}{|c|}{ Access feeder trip (home-side, $N=1086$ ) } \\
\hline Bicycle crash & 0.049 & 1.120 & 0.290 & $0.210 * * *$ & 21.074 & 0.000 \\
\hline Vehicle crash & $-0.071 *$ & 2.003 & 0.097 & $0.152 * * *$ & 9.311 & 0.002 \\
\hline Cycling & 0.051 & 1.193 & 0.275 & & & \\
\hline Walking & 0.038 & 0.613 & 0.434 & & & \\
\hline Bus & -0.004 & 0.008 & 0.929 & & & \\
\hline DBS & 0.028 & 0.457 & 0.499 & & & \\
\hline DBS vs. walking & $0.162 * * *$ & 10.068 & 0.002 & & & \\
\hline DBS vs. bus & 0.030 & 0.339 & 0.561 & & & \\
\hline Easy to take a bus & $-0.111^{* *}$ & 4.371 & 0.037 & & & \\
\hline Easy to find DBS & $0.113^{* *}$ & 4.299 & 0.038 & & & \\
\hline Physical activity & $0.119^{* * *}$ & 11.400 & 0.001 & & & \\
\hline \multicolumn{7}{|c|}{ Egress feeder trip (workplace-side, $N=1108$ ) } \\
\hline Bicycle crash & 0.040 & 0.813 & 0.367 & $-0.124^{* *}$ & 5.169 & 0.023 \\
\hline Vehicle crash & $-0.103 * *$ & 4.031 & 0.045 & $-0.187^{* * *}$ & 8.960 & 0.003 \\
\hline Cycling & 0.044 & 0.875 & 0.350 & & & \\
\hline Walking & 0.038 & 0.630 & 0.427 & & & \\
\hline Bus & -0.003 & 0.004 & 0.947 & & & \\
\hline DBS & 0.034 & 0.665 & 0.415 & & & \\
\hline DBS vs. walking & $0.146^{* * *}$ & 8.147 & 0.004 & & & \\
\hline DBS vs. bus & 0.045 & 0.754 & 0.385 & & & \\
\hline Easy to take a bus & 0.007 & 0.017 & 0.897 & & & \\
\hline Easy to find DBS & 0.049 & 0.785 & 0.376 & & & \\
\hline Physical activity & $0.123^{* * *}$ & 12.462 & 0.000 & & & \\
\hline
\end{tabular}

Table 4 reveals no significant difference in attitudes toward feeder modes (i.e., cycling, walking, bus, and DBS) between male and female metro users. However, compared with female metro users, male counterparts are more likely to hold an attitude that DBS is quicker than walking to connect the metro. Moreover, male metro users also have a higher willingness to carry out some daily physical activities than their female counterparts. Such a result is consistent with the work of Lee [76], which reveals that the female is less likely to be active than the male. Additionally, it is observed that the attitudes toward searching buses and DBS differ between male and female groups for their access trips connecting home and the metro. We found that female metro users think it is easier to take a bus but more difficult to search for DBS bikes around their home than male metro users. It is possible that compared with the female, the male is more likely to overestimate the bus waiting time, which is measured by a ratio of perceived waiting time to actual waiting time [77].

\subsection{MNL Modeling Results}

Tables 5 and 6 present the MNL modeling results for access and egress trips, respectively, using walking as the reference group. The Pseudo $\mathrm{R}^{2}$ of Access and Egress MNL models $(0.237$ and 0.206 ) indicate that the MNL models have acceptable goodness of fit. Obviously, the MNL models can explain more variances in the access integrated use than the egress integrated use.

\subsubsection{The Role of Perceived Traffic Safety}

The vehicle-related safety concern has significant effects on the feeder mode choice, while bicycle-related safety risk does not play such a significant role. The perception of bicycle-related crashes only affects mode choice between DBS and walking for access trips. A one-unit increase in the score of the perceived bicycle-related crash decreases the odds for choosing DBS relative to walking by $23.6 \%$ (= 1-0.764), holding all the other variables constant. 
A higher perceived risk of the vehicle-related crash encourages the choices of DBS and buses rather than walking to/from the metro station. For instance, high-speed vehicles crossing the intersections may make pedestrians feel dangerous. Thus, the exposures to vehicle-related crashes are deterrents for walk-metro users. Bikeway can provide cyclists with safety protection from the vehicle crash, and the bus is a sheltered mode protecting commuters from slight collisions with vehicles. For access trips, we see a $35.4 \%$ and $46.4 \%$ increase in the odds for opting for DBS and buses, respectively, relative to walking for a one-unit increase in the perceived risk of the vehicle-related crash, while the values for egress trips are $30.2 \%$ and $31.6 \%$, respectively. This finding indicates that metro passengers are more affected by vehicle-related safety risks for access trips than for egress trips.

\subsubsection{The Role of Attitude}

Specific attitudes toward transport modes are observed to have an essential role in determining mode choice. As many previous studies concluded, bike-sharing mostly replaces walking for travel $[78,79]$. Our results reveal that a positive attitude toward DBS and cycling behavior but a negative attitude toward walking can significantly promote the likelihood of adopting DBS rather than walking as the feeder mode. More specifically, every one-unit higher in the score of cycling attitude can increase the odds for choosing DBS relative to walking by $87.8 \%(=1.878-1)$ for access trips and $27.6 \%(=1.276-1)$ for egress trips; a one-unit increase in the DBS attitude score increased the odds for opting for DBS relative to walking by $127.9 \%(=2.279-1)$ and $60.9 \%(=1.609-1)$ for access and egress trips, respectively. However, the odds for adopting DBS relative to walking will decrease by more than $30 \%$ for each unit in an increase in the walking-attitude score (OR $=0.700$ in the Access model and $\mathrm{OR}=0.647$ in the Egress model). Similarly, by comparing the coefficients of the same variable, we find that favorable attitudes toward DBS and cycling behavior also promote the substitution effect of DBS to buses as the feeder mode. Moreover, it is found that the attitude toward buses does not significantly affect mode choice. We only observe that a negative attitude toward walking increases the possibility of choosing buses for an access trip, particularly when the bus service is easily perceived to be offered around the home. This observation is reasonable.

Relative attitudes between travel modes are also crucial to metro passengers' feeder mode choice. If metro users think that DBS is faster than walking to connect the metro station, they will have a higher possibility of adopting DBS as the feeder mode $(\mathrm{OR}=1.631$ in the Access model and OR $=1.921$ in the Egress model). Moreover, a relative attitude that DBS is quicker than buses can increase the odds of choosing DBS as an egress mode. Our results are consistent with the study by Heinen and Bohte [18].

Tables 5 and 6 also show significant effects of the attitude toward DBS/bus availability on the feeder mode choice, mostly applicable for the access trip scenario. It shows that, for access trips, an attitude of easy access to the bus stop can add the willingness to take buses rather than walk for connecting the metro. Moreover, a positive attitude of searching for DBS bike around the home significantly increases the odds of DBS-metro integration. This outcome indicates a self-reinforcing effect in terms of the attitudes toward the DBS/bus availability. Furthermore, the perception of ease of searching for DBS bikes is crucial for replacing walking with DBS for both access and egress trips. However, the attitude toward physical activity is insignificant in affecting the feeder mode choice.

\subsubsection{The Role of Socio-Demographic Characteristics}

The socio-demographic characteristics are strongly related to the feeder mode choice. This outcome is in line with existing literature [22,23,80]. More specifically, our results show that DBS is preferable for males than females to finish their access trips, while no significant difference exists between genders for egress trips. Age and income significantly affect the feeder mode choice of egress trips, but not that of access trips. Compared to those under 25 years, young adults ( 26 to 35 years) have a higher willingness to opt for DBS relative to walking $(\mathrm{OR}=1.745)$ in egress trips. However, older adults prefer using buses (relative to walking) for egress trips. Interestingly, we found that middle- and high-incomers (monthly income $>5000 \mathrm{RMB}$ ) are more likely to walk than taking buses as their major 
mode for access trips. Buses are usually crowded during peak hours and lack privacy, which is what high earners care about.

Table 5 shows that, compared with urban peers, suburban respondents are more likely to transfer by buses than walking for the access trip (home-to-metro); and that compared with suburban residents, urban peers are more likely to use DBS than walking for the access trip. The two findings are reasonable. On the one hand, metro accessibility is lower in suburban areas, and access distance to the metro station is longer. Suburban commuters cannot reach the metro by walking as their urban peers do, so buses are preferable for them (relative to walking). On the other hand, cycling infrastructures are more developed in urban areas than in suburban areas, leading to a higher willingness to transfer by DBS. Thus, DBS is more prevalent in cities than in suburban areas.

Table 6 indicates that for egress trips (metro-to-workplace), walking is more likely adopted in urban areas, while DBS and buses are more prevalent in suburban areas. Three possible reasons could be proposed. First, in urban areas, the dense distribution of the metro system in urban areas makes it unnecessary to transfer by DBS and buses because of the short transfer distance. Second, the heavy traffic condition in urban areas (e.g., traffic congestion) may be perceived to be unsafe by cyclists, whereas riding buses is time-consuming and unnecessary in most cases in urban areas of Shenzhen, a quintessential transit-dependent city. Third, the high quality of pedestrian infrastructures in urban areas means high walkability, which is friendly to pedestrians.

Moreover, transfer distance is significantly associated with the feeder mode choice, which is in agreement with previous studies $[16,23]$. Our results also show that DBS and buses are attractive for long-distance trips in the two scenarios. Additionally, the coefficient of the variable Transfer distance in the Bus model is larger than that in the DBS model, indicating that the substitution effect between bus and walking is more significant than that between DBS and walking when the transfer distance is reasonably long.

Table 5. Results of the access MNL model (reference group: walking, $N=1086$ ).

\begin{tabular}{|c|c|c|c|c|c|c|c|c|}
\hline \multirow{2}{*}{ Variable } & \multicolumn{4}{|c|}{ DBS } & \multicolumn{4}{|c|}{ Bus } \\
\hline & Coef. & Odds Ratio & Std. & $\mathbf{z}$ & Coef. & Odds Ratio & Std. & $\mathbf{z}$ \\
\hline \multicolumn{9}{|c|}{ Safety and attitude variables } \\
\hline Bicycle crash & $-0.269 * *$ & 0.764 & 0.146 & -1.99 & 0.028 & 1.028 & 0.135 & 0.19 \\
\hline Vehicle crash & $0.303 * *$ & 1.354 & 0.135 & 2.39 & $0.381^{* * *}$ & 1.464 & 0.127 & 2.82 \\
\hline Cycling & $0.630 * * *$ & 1.878 & 0.164 & 3.84 & 0.069 & 1.071 & 0.164 & 0.42 \\
\hline Walking & $-0.357^{* * *}$ & 0.700 & 0.148 & -2.60 & $-0.285 *$ & 0.752 & 0.138 & -1.92 \\
\hline Bus & -0.018 & 0.982 & 0.282 & -0.07 & 0.318 & 1.374 & 0.258 & 1.13 \\
\hline DBS & $0.824 * * *$ & 2.279 & 0.180 & 4.14 & -0.213 & 0.809 & 0.199 & -1.18 \\
\hline DBS vs. walking & $0.489 * * *$ & 1.631 & 0.158 & 3.13 & $0.277 *$ & 1.319 & 0.156 & 1.75 \\
\hline DBS vs. bus & -0.028 & 0.972 & 0.183 & -0.16 & -0.260 & 0.771 & 0.171 & -1.42 \\
\hline Easy to take a bus & -0.396 ** & 0.673 & 0.201 & -2.36 & $0.599 * * *$ & 1.821 & 0.168 & 2.98 \\
\hline Easy to find DBS & $0.605^{* * *}$ & 1.832 & 0.129 & 5.05 & -0.098 & 0.906 & 0.120 & -0.76 \\
\hline Physical activity & -0.263 & 0.768 & 0.192 & -1.38 & -0.153 & 0.858 & 0.191 & -0.80 \\
\hline \multicolumn{9}{|l|}{ Control variables } \\
\hline \multicolumn{9}{|c|}{ Gender (reference: female) } \\
\hline Male & $0.342 *$ & 1.407 & 0.222 & 1.59 & -0.181 & 0.835 & 0.215 & -0.81 \\
\hline \multicolumn{9}{|c|}{ Age (reference: under 25 years) } \\
\hline $26-35$ years & 0.187 & 1.206 & 0.263 & 0.78 & 0.138 & 1.148 & 0.241 & 0.53 \\
\hline $36-45$ years & -0.468 & 0.626 & 0.358 & -1.28 & 0.366 & 1.442 & 0.367 & 1.02 \\
\hline Over 46 years & -0.387 & 0.679 & 0.644 & -0.63 & -0.015 & 0.985 & 0.613 & -0.02 \\
\hline \multicolumn{9}{|c|}{ Education (reference: middle school or below) } \\
\hline High school & -0.137 & 0.872 & 0.758 & -0.19 & -0.379 & 0.684 & 0.728 & -0.50 \\
\hline College/University & -0.276 & 0.759 & 0.718 & -0.40 & -0.573 & 0.564 & 0.694 & -0.80 \\
\hline Graduate institute & -0.523 & 0.593 & 0.786 & -0.69 & -0.419 & 0.658 & 0.753 & -0.53 \\
\hline
\end{tabular}


Table 5. Cont

\begin{tabular}{|c|c|c|c|c|c|c|c|c|}
\hline \multirow{2}{*}{ Variable } & \multicolumn{4}{|c|}{ DBS } & \multicolumn{4}{|c|}{ Bus } \\
\hline & Coef. & Odds Ratio & Std. & $\mathrm{z}$ & Coef. & Odds Ratio & Std. & $\mathrm{z}$ \\
\hline \multicolumn{9}{|c|}{ Income (reference: <4999 RMB) } \\
\hline 5000 to 9999 RMB & 0.132 & 1.141 & 0.323 & 0.39 & $-0.608 *$ & 0.544 & 0.336 & -1.89 \\
\hline 10,000 to 14,999 RMB & 0.206 & 1.229 & 0.401 & 0.54 & $-1.134^{* * *}$ & 0.322 & 0.379 & -2.83 \\
\hline$>15,000 \mathrm{RMB}$ & -0.239 & 0.788 & 0.413 & -0.56 & $-0.781 *$ & 0.458 & 0.423 & -1.89 \\
\hline \multicolumn{9}{|c|}{ Bicycle ownership (reference: no) } \\
\hline Yes & 0.203 & 1.225 & 0.322 & 0.65 & $0.600 *$ & 1.822 & 0.314 & 1.86 \\
\hline \multicolumn{9}{|c|}{ Home location (reference: urban area) } \\
\hline Suburban area & $-0.351 *$ & 0.704 & 0.236 & -1.69 & $0.397^{*}$ & 1.487 & 0.208 & 1.68 \\
\hline Transfer distance & $0.972 * * *$ & 1.001 & 0.158 & 5.98 & $1.298^{* * *}$ & 1.001 & 0.163 & 8.21 \\
\hline Intercept & $-6.378^{* * *}$ & 0.002 & 1.249 & -5.16 & $-3.678^{* * *}$ & 0.025 & 1.237 & -2.95 \\
\hline Pseudo $\mathrm{R}^{2}$ & \multicolumn{8}{|c|}{0.237} \\
\hline Log-likelihood & \multicolumn{8}{|c|}{-661.507} \\
\hline
\end{tabular}

Table 6. Results of the egress MNL model (reference group: walking, $N=1108$ ).

\begin{tabular}{|c|c|c|c|c|c|c|c|c|}
\hline \multirow{2}{*}{ Variable } & \multicolumn{4}{|c|}{ DBS } & \multicolumn{4}{|c|}{ Bus } \\
\hline & Coef. & Odds Ratio & Std. & $\mathbf{z}$ & Coef. & Odds Ratio & Std. & $\mathbf{z}$ \\
\hline \multicolumn{9}{|c|}{ Safety and attitude variables } \\
\hline Bicycle crash & -0.186 & 0.830 & 0.163 & -1.38 & -0.089 & 0.915 & 0.135 & -0.55 \\
\hline Vehicle crash & $0.264^{* *}$ & 1.302 & 0.144 & 2.13 & $0.275 *$ & 1.316 & 0.124 & 1.91 \\
\hline Cycling & $0.244 *$ & 1.276 & 0.181 & 1.65 & -0.015 & 0.985 & 0.147 & -0.08 \\
\hline Walking & $-0.435^{* * *}$ & 0.647 & 0.163 & -3.23 & -0.255 & 0.775 & 0.135 & -1.56 \\
\hline Bus & 0.029 & 1.029 & 0.322 & 0.11 & 0.140 & 1.150 & 0.259 & 0.43 \\
\hline DBS & $0.475^{* * *}$ & 1.609 & 0.200 & 2.60 & 0.068 & 1.070 & 0.183 & 0.34 \\
\hline DBS vs. walking & $0.653^{* * *}$ & 1.921 & 0.170 & 4.02 & 0.079 & 1.082 & 0.162 & 0.47 \\
\hline DBS vs. bus & $0.428^{* *}$ & 1.535 & 0.201 & 2.42 & -0.127 & 0.881 & 0.177 & -0.63 \\
\hline Easy to take a bus & -0.202 & 0.817 & 0.204 & -1.27 & 0.066 & 1.069 & 0.160 & 0.33 \\
\hline Easy to find DBS & $0.261^{* *}$ & 1.298 & 0.135 & 2.35 & 0.053 & 1.055 & 0.111 & 0.40 \\
\hline Physical activity & 0.236 & 1.266 & 0.213 & 1.26 & 0.047 & 1.048 & 0.187 & 0.22 \\
\hline \multicolumn{9}{|l|}{ Control variables } \\
\hline \multicolumn{9}{|c|}{ Gender (reference: female) } \\
\hline Male & 0.141 & 1.152 & 0.246 & 0.68 & -0.034 & 0.967 & 0.208 & -0.14 \\
\hline \multicolumn{9}{|c|}{ Age (reference: under 25 years) } \\
\hline $26-35$ years & $0.557 * *$ & 1.745 & 0.296 & 2.32 & -0.015 & 0.986 & 0.240 & -0.05 \\
\hline $36-45$ years & 0.387 & 1.473 & 0.385 & 1.14 & 0.791 ** & 2.207 & 0.340 & 2.06 \\
\hline Over 46 years & 0.302 & 1.353 & 0.570 & 0.51 & $1.026^{*}$ & 2.789 & 0.594 & 1.80 \\
\hline \multicolumn{9}{|c|}{ Education (reference: middle school or below) } \\
\hline High school & -0.321 & 0.725 & 0.697 & -0.48 & -1.021 & 0.360 & 0.671 & -1.46 \\
\hline College/University & -0.996 & 0.369 & 0.647 & -1.56 & $-1.381 * *$ & 0.251 & 0.638 & -2.13 \\
\hline Graduate institute & $-1.419 *$ & 0.242 & 0.754 & -1.94 & $-1.299 *$ & 0.273 & 0.730 & -1.72 \\
\hline \multicolumn{9}{|c|}{ Income (reference: <4999 RMB) } \\
\hline 5000 to $9999 \mathrm{RMB}$ & 0.028 & 1.029 & 0.367 & 0.09 & -0.219 & 0.803 & 0.313 & -0.60 \\
\hline 10,000 to $14,999 \mathrm{RMB}$ & -0.502 & 0.605 & 0.444 & -1.36 & -0.589 & 0.555 & 0.368 & -1.33 \\
\hline$>15,000 \mathrm{RMB}$ & $-1.180 * * *$ & 0.307 & 0.476 & -2.78 & -0.706 & 0.493 & 0.425 & -1.48 \\
\hline \multicolumn{9}{|c|}{ Bicycle ownership (reference: no) } \\
\hline Yes & 0.215 & 1.240 & 0.341 & 0.72 & 0.406 & 1.500 & 0.298 & 1.19 \\
\hline \multicolumn{9}{|c|}{ Workplace location (reference: urban area) } \\
\hline Suburban area & $0.445^{*}$ & 1.560 & 0.272 & 1.91 & $0.489 *$ & 1.630 & 0.233 & 1.80 \\
\hline Transfer distance & $1.143 * * *$ & 1.001 & 0.194 & 5.96 & $1.605^{* * *}$ & 1.002 & 0.192 & 8.29 \\
\hline Intercept & $-6.796 * * *$ & 0.001 & 1.275 & -5.42 & $-2.282 *$ & 0.102 & 1.255 & -1.79 \\
\hline Pseudo $\mathrm{R}^{2}$ & \multicolumn{8}{|c|}{0.206} \\
\hline Log-likelihood & & & & -622 & 990 & & & \\
\hline
\end{tabular}




\section{Discussion}

Like many other transit modes, the metro offers commuters stop-to-stop services instead of door-to-door services. First- and last-mile issues are, therefore, inevitable for metro trips [10]. A synergy between the metro and other travel modes, either motorized (e.g., bus and car) or non-motorized (e.g., walking and cycling), brings potentials to promote urban mobility through addressing the firstand last-mile problem $[11,21]$. Identifying the determinants of the feeder mode choice is, therefore, dispensable for understanding the first-/last-mile behavior of metro commuters.

This study contributes to the literature in three aspects. First, we explored the feeder mode choices of metro commuters in the Chinese mega-city context featured with unique characteristics of feeder behaviors, thereby generating diverse targeted implications for improving the seamless connection of metro transit. Second, the discussion of DBS, the newly emerged transport mode that has profoundly reshaped feeder mode choices, enriches the traditional transport research on multimodal behavior. Third, we compared the effects of traffic safety perception and attitudes on the feeder mode choices between access and egress feeder trip scenarios, which have been scarcely discussed in the literature.

This study provides a useful reference to guide metro users to choose reasonable feeder modes for connecting the metro transit with optimal utilities. Its findings also provide DBS/bus operators and the local government with a valuable reference for the management and improvement of the firstand last-mile. For instance, setting sideways and exclusive bikeways may improve safety perception, thereby encouraging active travel modes (e.g., walking and cycling) for connecting the metro transit [24]. Appropriate distributions of DBS bikes and bus stops near origins/destinations in metro catchment areas and close to metro entrances/exits are indispensable for fostering a good attitude toward DBS/bus usage [16]. During peak hours at metro entrances/exits, DBS bikes are excessively allocated and parked disorderly, whereas the queue for the bus is usually long, clogging the road. Thus, effective management for metro connection around metro entrances/exits is necessarily provided by local transport departments or bureaus. Moreover, available feeder services (e.g., bus lines, fare discount scheme, smart card, and real-time information system) and people-friendly facilities (e.g., bicycle parking space, protected shelters, benches, sidewalks, and exclusive bikeways) in metro catchment areas are suggested to be offered by local transport departments or bureaus [24,38]. More attention and efforts should be paid to suburban areas where feeder services and facilities are less equipped. These measures aiming at a seamless metro transit connection contribute to promoting metro usage or facilitating the modal shift from the car to the metro transit, thereby benefiting sustainable development urban transport. Furthermore, in today's era with diversified last-mile travel choices, we hope that our topic can ignite a tremendous fascination from local and international researchers.

However, there are some limitations that deserved future research. First, limited by the questionnaire design, we only include two traffic safety variables (bicycle crash and vehicle crash) in the MNL models. As such, more perceived safety factors such as in-vehicle safety in buses and cars should be considered in future studies [43]. Second, attitude factors are insufficiently considered. For example, the attitudes toward economic cost and environmental awareness, which this study fails to capture, may affect the decision-making process of feeder trip mode choice. Third, attitudes may be shaped by objective, physical factors. For example, the attitude towards bus/PBS availability is likely related to the objective level of service. In a similar vein, perceived traffic safety is possibly associated with the actual number of accidents. As such, exploring the interplay between objective factors and (subjective) attitudes (e.g., objectively measured and perceived service quality) is worthy of examination. Fourth, future studies can be devoted to exploring the relationships between traffic safety, attitude, socio-demographic characteristics, and feeder mode choice by revealing the underlying mediation or moderation effects. Last but not least, as travel behavior is jointly shaped by socio-economic variables, the physical environment (built environment + natural environment), and perceptions or attitudes, examining the relative importance of all the independent variables and determining which category plays a larger role in shaping travel behavior is worthy of investigation. Machine learning techniques 
(e.g., support vector machine, decision tree, random forest, gradient boosting decision tree, and extreme gradient boosting model) are recommended to be adopted in future studies.

\section{Conclusions}

In a departure from existing literature, this study explores how perceived traffic safety and attitude factors are associated with metro commuters' feeder mode choice during the morning peak time. Our analysis results basically answer our four research questions (see Section 1) and can be listed as follows. (1) Walking is the most frequently used mode for connecting the metro (accounting for over $70 \%$ ), followed by DBS and buses. The high feeder mode share of walking and DBS is unique in the context of Mainland Chinese mega cities, which differs from European and North American cities; (2) Variances in traffic safety perception and attitude exist across gender and space; (3) The variance in the attitude toward the feeder mode between genders is minimal (or subtle), but men's attitude toward the DBS/bus availability remarkably differs from women's; (4) The vehicle-related crash risk usually discourages walking but supports the DBS and buses as transfer modes, whereas the bicycle-related crash is a barrier of transfer by DBS for access trips; (5) Positive attitudes toward cycling and DBS make DBS competitive as a feeder mode. A good attitude toward walking promotes walk-metro integration, but the attitude toward buses does not matter in the feeder mode choice; and (6) Perceived traffic safety and attitudes toward the mode play different roles in shaping first- and last-mile mode choices.

Author Contributions: Conceptualization, Y.G. (Yuanyuan Guo) and L.Y.; Methodology, Y.G. (Yuanyuan Guo) and L.Y.; Software, Y.G. (Yuanyuan Guo) and L.Y.; Validation, W.H. and Y.G. (Yi Guo); Formal analysis, Y.G. (Yuanyuan Guo); Writing-original draft preparation, Y.G. (Yuanyuan Guo) and L.Y.; Writing—review and editing, W.H. and Y.G. (Yi Guo); Supervision, L.Y.; Project administration, Y.G. (Yuanyuan Guo) and L.Y. All authors have read and agreed to the published version of the manuscript.

Funding: This study is sponsored by the National Natural Science Foundation of China (No. 51778530).

Acknowledgments: The authors are grateful to the three reviewers for their helpful comments.

Conflicts of Interest: The authors declare no conflict of interest.

\section{References}

1. Huang, W.; Guo, Y.; Xu, X. Evaluation of real-time vehicle energy consumption and related emissions in China: A case study of the Guangdong-Hong Kong-Macao greater Bay Area. J. Clean. Prod. 2020, 263, 121583. [CrossRef]

2. Sommar, J.N.; Johansson, C.; Lövenheim, B.; Markstedt, A.; Strömgren, M.; Forsberg, B. Potential effects on travelers' air pollution exposure and associated mortality estimated for a mode shift from car to bicycle commuting. Int. J. Environ. Res. Public Health 2020, 17, 7635. [CrossRef]

3. Wang, K.; Wang, X. Providing sports venues on mainland China: Implications for promoting leisure-time physical activity and national fitness policies. Int. J. Environ. Res. Public Health 2020, 17, 5136. [CrossRef]

4. Cheng, Y.H.; Liu, K.C. Evaluating bicycle-transit users' perceptions of intermodal inconvenience. Transp. Res. Part A Policy Pract. 2012, 46, 1690-1706. [CrossRef]

5. Yang, L.; Chu, X.; Gou, Z.; Yang, H.; Lu, Y.; Huang, W. Accessibility and proximity effects of bus rapid transit on housing prices: Heterogeneity across price quantiles and space. J. Transp. Geogr. 2020, 88, 102850. [CrossRef]

6. Yang, L.; Chau, K.W.; Szeto, W.Y.; Cui, X.; Wang, X. Accessibility to transit, by transit, and property prices: Spatially varying relationships. Transp. Res. Part D Transp. Environ. 2020, 85, 102387. [CrossRef]

7. Qin, H.; Guan, H.; Wu, Y. Analysis of park-and-ride decision behavior based on Decision Field Theory. Transp. Res. Part F Psychol. Behav. 2013, 18, 199-212. [CrossRef]

8. Wang, R.; Chen, L. Bicycle-transit integration in the United States, 2001-2009. J. Public Transp. 2013, 16, 95-119. [CrossRef] 
9. Park, K.; Choi, D.A.; Tian, G.; Ewing, R. Not parking lots but parks: A joint association of parks and transit stations with travel behavior. Int. J. Environ. Res. Public Health 2019, 16, 547. [CrossRef]

10. Zhao, R.; Yang, L.; Liang, X.; Guo, Y.; Lu, Y.; Zhang, Y.; Ren, X. Last-mile travel mode choice: Data-mining hybrid with multiple attribute decision making. Sustainability 2019, 11, 6733. [CrossRef]

11. Duncan, M.; Cook, D. Is the provision of park-and-ride facilities at light rail stations an effective approach to reducing vehicle kilometers traveled in a US context? Transp. Res. Part A Policy Pract. 2014, 66, 65-74. [CrossRef]

12. Pucher, J.; Buehler, R. Integrating bicycling and public transport in North America. J. Public Transp. 2009, 12, 79-104. [CrossRef]

13. Wu, S.S.; Zhuang, Y.; Chen, J.; Wang, W.; Bai, Y.; Lo, S.M. Rethinking bus-to-metro accessibility in new town development: Case studies in Shanghai. Cities 2019, 94, 211-224. [CrossRef]

14. Wang, J.J.; Po, K. Bus routing strategies in a transit market: A case study of Hong Kong. J. Adv. Transp. 2001, 35, 259-288. [CrossRef]

15. Ma, T.; Liu, C.; Erdoğan, S. Bicycle sharing and transit: Does Capital Bikeshare affect Metrorail ridership in Washington, D.C.? Transp. Res. Rec. J. Transp. Res. Board 2015, 2534, 1-9. [CrossRef]

16. Guo, Y.; He, S.Y. Built environment effects on the integration of dockless bike-sharing and the metro. Transp. Res. Part D Transp. Environ. 2020, 83, 102335. [CrossRef]

17. Hern, S.O.; Estgfaeller, N. A scientometric review of powered micromobility. Sustainability 2020, $12,9505$.

18. Heinen, E.; Bohte, W. Multimodal commuting to work by public transport and bicycle: Attitudes toward mode choice. Transp. Res. Rec. J. Transp. Res. Board 2014, 2015, 111-122. [CrossRef]

19. Bachand-Marleau, J.; Larsen, J.; El-Geneidy, A. Much-anticipated marriage of cycling and transit. Transp. Res. Rec. J. Transp. Res. Board 2011, 2247, 109-117. [CrossRef]

20. Chalermpong, S.; Wibowo, S.S. Transit station access trips and factors affecting propensity to walk to transit stations in Bangkok, Thailand. J. East. Asia Soc. Transp. Stud. 2007, 7, 1806-1819.

21. Cervero, R. Walk-and-ride: Factors influencing pedestrian access to transit. J. Public Transp. 2001, 3, 1-23. [CrossRef]

22. Ji, Y.; Fan, Y.; Ermagun, A.; Cao, X.; Wang, W.; Das, K. Public bicycle as a feeder mode to rail transit in China: The role of gender, age, income, trip purpose, and bicycle theft experience. Int. J. Sustain. Transp. 2017, 11, 1-23. [CrossRef]

23. Zhao, P.; Li, S. Bicycle-metro integration in a growing city: The determinants of cycling as a transfer mode in metro station areas in Beijing. Transp. Res. Part A Policy Pract. 2017, 99, 46-60. [CrossRef]

24. Griffin, G.P.; Sener, I.N. Planning for bike share connectivity to rail transit. J. Public Transp. 2016, 19, 1-22. [CrossRef]

25. Ajzen, I. The theory of planned behavior. Organ. Behav. Hum. Decis. Process. 1991, 50, 179-211. [CrossRef]

26. Elias, W.; Shiftan, Y. The influence of individual's risk perception and attitudes on travel behavior. Transp. Res. Part A Policy Pract. 2012, 46, 1241-1251. [CrossRef]

27. Johansson, M.V.; Heldt, T.; Johansson, P. The effects of attitudes and personality traits on mode choice. Transp. Res. Part A Policy Pract. 2006, 40, 507-525. [CrossRef]

28. Guliani, A.; Mitra, R.; Buliung, R.N.; Larsen, K.; Faulkner, G.E.J. Gender-based differences in school travel mode choice behaviour: Examining the relationship between the neighbourhood environment and perceived traffic safety. J. Transp. Heal. 2015, 2, 502-511. [CrossRef]

29. Bagley, M.N.; Mokhtarian, P.L. The impact of residential neighborhood type on travel behavior: A structural equations modeling approach. Ann. Reg. Sci. 2002, 36, 279-297. [CrossRef]

30. Schwanen, T.; Mokhtarian, P.L. What affects commute mode choice: Neighborhood physical structure or preferences toward neighborhoods? J. Transp. Geogr. 2005, 13, 83-99. [CrossRef]

31. McMillan, T.E. The relative influence of urban form on a child's travel mode to school. Transp. Res. Part A Policy Pract. 2007, 41, 69-79. [CrossRef]

32. Arroyo, R.; Ruiz, T.; Mars, L.; Rasouli, S.; Timmermans, H. Influence of values, attitudes towards transport modes and companions on travel behavior. Transp. Res. Part F Traffic Psychol. Behav. 2020, 71, 8-22. [CrossRef]

33. Lee, J.M. Exploring Walking behavior in the streets of New York City using hourly pedestrian count data. Sustainability 2020, 12, 7863. [CrossRef] 
34. Krizek, K.; Stonebraker, E. Bicycling and transit a marriage unrealized. Transp. Res. Rec. J. Transp. Res. Board 2010, 2144, 161-167. [CrossRef]

35. Singleton, P.; Clifton, K. Exploring synergy in bicycle and transit use. Transp. Res. Rec. J. Transp. Res. Board 2014, 2417, 92-102. [CrossRef]

36. Martens, K. Promoting bike-and-ride: The Dutch experience. Transp. Res. Part A Policy Pract. 2007, 41, 326-338. [CrossRef]

37. Guo, Y.; Yang, L.; Lu, Y.; Zhao, R. Dockless bike-sharing as a feeder mode of metro commute? The role of the feeder-related built environment: Analytical framework and empirical evidence. Sustain. Cities Soc. 2020, 104947.

38. Rastogi, R.; Krishna Rao, K.V. Travel characteristics of commuters accessing transit: Case study. J. Transp. Eng. 2003, 129, 684-694. [CrossRef]

39. Pongprasert, P.; Kubota, H. Switching from motorcycle taxi to walking: A case study of transit station access in Bangkok, Thailand. IATSS Res. 2017, 41, 182-190. [CrossRef]

40. Chandra, S.; Bari, M.E.; Devarasetty, P.C.; Vadali, S. Accessibility evaluations of feeder transit services. Transp. Res. Part A Policy Pract. 2013, 52, 47-63. [CrossRef]

41. Schiller, P.L.; Kenworthy, J. An Introduction to Sustainable Transportation: Policy, Planning and Implementation, 2nd ed.; Routledge: London, UK, 2010.

42. Campbell, A.A.; Cherry, C.R.; Ryerson, M.S.; Yang, X. Factors influencing the choice of shared bicycles and shared electric bikes in Beijing. Transp. Res. Part C Emerg. Technol. 2016, 67, 399-414. [CrossRef]

43. Salonen, A.O. Passenger's subjective traffic safety, in-vehicle security and emergency management in the driverless shuttle bus in Finland. Transp. Policy 2018, 61, 106-110. [CrossRef]

44. Gargoum, S.A.; El-basyouny, K. Exploring the association between speed and safety: A path analysis approach. Accid. Anal. Prev. 2016, 93, 32-40. [CrossRef]

45. Giles-Corti, B.; Wood, G.; Pikora, T.; Learnihan, V.; Bulsara, M.; Van Niel, K.; Timperio, A.; McCormack, G.; Villanueva, K. School site and the potential to walk to school: The impact of street connectivity and traffic exposure in school neighborhoods. Heal. Place 2011, 17, 545-550. [CrossRef]

46. Hamed, M.M.; Al Rousan, T.M. Impact of perceived risk on urban commuters' route choices. Road Transp. Res. 1998, 7, 46-62.

47. Syafriharti, R.; Kombaitan, B.; Kusumantoro, I.P.; Syabri, I. Relationship between train users' perceptions of walkability with access and egress mode choice. In MATEC Web of Conferences; EDP Sciences: Les Ulis, France, 2018; Volume 147, pp. 1-9.

48. Adams, J.G.U. Evaluating the effectiveness of road safety measures. Traffic Eng. Control 1988, 29, $344-352$.

49. Cho, G.; Rodríguez, D.A.; Khattak, A.J. The role of the built environment in explaining relationships between perceived and actual pedestrian and bicyclist safety. Accid. Anal. Prev. 2009, 41, 692-702. [CrossRef]

50. Kerr, J.; Emond, J.A.; Badland, H.; Reis, R.; Sarmiento, O.; Carlson, J.; Sallis, J.F.; Cerin, E.; Cain, K.; Conway, T.; et al. Perceived neighborhood environmental attributes associated with walking and cycling for transport among adult residents of 17 cities in 12 countries: The IPEN study. Environ. Health Perspect. 2016, 124, 290-298. [CrossRef]

51. Zhang, C.Q.; Zhang, R.; Gan, Y.; Li, D.; Rhodes, R.E. Predicting transport-related cycling in Chinese employees using an integration of perceived physical environment and social cognitive factors. Transp. Res. Part F Traffic Psychol. Behav. 2019, 64, 424-439. [CrossRef]

52. Van Wee, B. Verkeer en transport. In Verkeer en Vervoer in hoofdlijnen (Outlining Traffic and Transport); Van Wee, B., Anne Annema, J., Eds.; Coutinho: Bussum, The Netherlands, 2009.

53. Schepers, P.; Hagenzieker, M.; Methorst, R.; Van Wee, B.; Wegman, F. A conceptual framework for road safety and mobility applied to cycling safety. Accid. Anal. Prev. 2014, 62, 331-340. [CrossRef]

54. Dill, J.; Carr, T. Bicycle commuting and facilities in major U.S. cities: If you build them, commuters will use them. Transp. Res. Rec. J. Transp. Res. Rec. 2003, 116-123. [CrossRef]

55. Aziz, H.M.A.; Nagle, N.N.; Morton, A.M.; Hilliard, M.R.; White, D.A.; Stewart, R.N. Exploring the impact of walk-bike infrastructure, safety perception, and built-environment on active transportation mode choice: A random parameter model using New York City commuter data. Transportation 2018, 45, 1207-1229. [CrossRef] 
56. Pyrialakou, V.D.; Gkartzonikas, C.; Gatlin, J.D.; Gkritza, K. Perceptions of safety on a shared road: Driving, cycling, or walking near an autonomous vehicle. J. Safety Res. 2020, 72, 249-258. [CrossRef]

57. Morales, J.F.; Moya, M.; Gaviria, E.; Cuadrado, I. Psicología Social; McGraw-Hill: Madrid, Spain, 2007.

58. Eagly, A.H.; Chaiken, S. The Psychology of Attitudes; Harcourt Brace Jovanovich College Publishers: Fort Worth, TX, USA, 1993; ISBN 0155000977.

59. Tran, Y.; Yamamoto, T.; Sato, H.; Miwa, T.; Morikawa, T. The analysis of influences of attitudes on mode choice under highly unbalanced mode share patterns. J. Choice Model. 2020, 36, 100227. [CrossRef]

60. Fishbein, M.; Ajzen, I. Belief, Attitude, Intention, and Behavior: An Introduction to Theory and Research; Addison-Wesley: Reading, MA, USA, 1975.

61. Gärling, T.; Gillholm, R.; Gärling, A. Reintroducing attitude theory in travel behavior research: The validity of an interactive interview procedure to predict car use. Transportation 1998, 25, 129-146. [CrossRef]

62. Hunecke, M.; Haustein, S.; Böhler, S.; Grischkat, S. Attitude-based target groups to reduce the ecological impact of daily mobility behavior. Environ. Behav. 2010, 42, 3-43. [CrossRef]

63. Ye, R.; Titheridge, H. Satisfaction with the commute: The role of travel mode choice, built environment and attitudes. Transp. Res. Part D Transp. Environ. 2017, 52, 535-547. [CrossRef]

64. Thøgersen, J. Understanding repetitive travel mode choices in a stable context: A panel study approach. Transp. Res. Part A Policy Pract. 2006, 40, 621-638. [CrossRef]

65. Beirão, G.; Sarsfield Cabral, J.A. Understanding attitudes towards public transport and private car: A qualitative study. Transp. Policy 2007, 14, 478-489. [CrossRef]

66. He, S.Y.; Thøgersen, J. The impact of attitudes and perceptions on travel mode choice and car ownership in a Chinese megacity: The case of Guangzhou. Res. Transp. Econ. 2017, 62, 57-67. [CrossRef]

67. Tran, Y.; Yamamoto, T.; Sato, H. The influences of environmentalism and attitude towards physical activity on mode choice: The new evidences. Transp. Res. Part A Policy Pract. 2020, 134, 211-226. [CrossRef]

68. Liu, D.; Du, H.; Southworth, F.; Ma, S. The influence of social-psychological factors on the intention to choose low-carbon travel modes in Tianjin, China. Transp. Res. Part A Policy Pract. 2017, 105, 42-53. [CrossRef]

69. Bao, Z.; Lu, W. Developing efficient circularity for construction and demolition waste management in fast emerging economies: Lessons learned from Shenzhen, China. Sci. Total Environ. 2020, 724, 138264. [CrossRef]

70. Xie, M. Shenzhen Ranks First in Urban Rail Transit Network Density in China with the Average Daily Passenger Flow of the Whole Network of 5.568 Million in 2019. Available online: http://k.sina.com.cn/article_ 1677991972_6404202402000n77w.html?from=news\&subch=onews (accessed on 1 May 2020).

71. Cerin, E.; Saelens, B.E.; Sallis, J.F.; Frank, L.D. Neighborhood Environment Walkability Scale: Validity and development of a short form. Med. Sci. Sports Exerc. 2006, 38, 1682. [CrossRef]

72. Nickkar, A.; Banerjee, S.; Chavis, C.; Bhuyan, I.A.; Barnes, P. A spatial-temporal gender and land use analysis of bikeshare ridership: The case study of Baltimore City. City, Cult. Soc. 2019, 18, 100291. [CrossRef]

73. Washington, S.P.; Karlaftis, M.G.; Mannering, F.L. Statistical and Econometric Methods for Transportation Data Analysis, 2nd ed.; Chapman and Hall/CRC: Boca Raton, FL, USA, 2011.

74. Ham, N.; Field, J.; Kirkwood, B. Gender differences and areas of common concern in the driving behaviors and attitudes of adolescents. J. Safety Res. 1996, 27, 163-173.

75. Najaf, P.; Thill, J.C.; Zhang, W.; Fields, M.G. City-level urban form and traffic safety: A structural equation modeling analysis of direct and indirect effects. J. Transp. Geogr. 2018, 69, 257-270. [CrossRef]

76. Lee, Y.S. Gender differences in physical activity and walking among older adults. J. Women Aging 2005, 17, 55-70. [CrossRef] [PubMed]

77. Psarros, I.; Kepaptsoglou, K.; Karlaftis, M.G. An empirical investigation of passenger wait time perceptions using hazard-based duration models. J. Public Transp. 2011, 14, 109-122. [CrossRef]

78. Shaheen, S.; Zhang, H.; Martin, E.; Guzman, S. China's Hangzhou public bicycle understanding: Early adoption and behavioral response to bikesharing. Transp. Res. Rec. J. Transp. Res. Board 2011, 2247, 33-41. [CrossRef] 
79. Fishman, E.; Washington, S.; Haworth, N. Bikeshare's impact on active travel: Evidence from the United States, Great Britain, and Australia. J. Transp. Heal. 2014, 2, 135-142. [CrossRef]

80. Lin, J.; Zhao, P.; Takada, K.; Li, S.; Yai, T.; Chen, C. Built environment and public bike usage for metro access: A comparison of neighborhoods in Beijing, Taipei, and Tokyo. Transp. Res. Part D Transp. Environ. 2018, 63, 209-221. [CrossRef]

Publisher's Note: MDPI stays neutral with regard to jurisdictional claims in published maps and institutional affiliations.

(C) 2020 by the authors. Licensee MDPI, Basel, Switzerland. This article is an open access article distributed under the terms and conditions of the Creative Commons Attribution (CC BY) license (http://creativecommons.org/licenses/by/4.0/). 